\title{
Field Measurement of the Motorcycle's Key Dimensions Using Simple Method and in-House Fabricated Instrument
}

\author{
Muthiah Arunachalam, Chirapriya Mondal, Sougata Karmakar* \\ Department of Design, Indian Institute of Technology (IIT) Guwahati, Guwahati 781039, Assam, India
}

Corresponding Author Email: karmakar.sougata@iitg.ac.in

https://doi.org/10.18280/i2m.190403

Received: 9 June 2020

Accepted: 4 August 2020

\section{Keywords:}

design, human factors, innovation, motorcycle simulator, measurement, dimensional database

\begin{abstract}
Out of many plausible causative factors for the spike in accidents, lack of riding skills is reported to be a significant reason for motorcycle mishaps. The riding skills can be improved through better availability of training facilities (simulator). Non-availability of the dimensional database (of different types of motorcycles), which are essential for simulator design, makes it difficult for the designers/ engineers to build the commercially available cheaper motorcycle-simulators. Moreover, the available measuring techniques and devices are costly and unable to satisfy motorcycle measurement's diverse requirements. Thus, the present research aimed to prepare the dimensional database of motorcycles using an in-house fabricated measuring instrument. Following the adaptive design method, the alpha prototype of a laser-pointer-based measuring instrument was developed. The calibrated device was used for measuring the dimensions associated with the handlebar, seat, and footrest of the 23 different motorcycles under study. Detailed (linear, angular, and circumferential) dimensions of the handlebar, seat, and footrest were measured using sliding calipers and protractors. Generated dimensional databases of 18 critical dimensions from the handlebar, seat, and footrest of the 23 different standardmotorcycles would be useful for deciding the motorcycle simulator's dimensions.
\end{abstract}

\section{INTRODUCTION}

Amongst 750 billion world population, $49 \%$ of all road traffic deaths comprise pedestrians, cyclists, and the rest related to motorcycles [1]. Out of $49 \%$ of all road traffic deaths, deaths related to motorcycles comprise 23\%, which means 125 billion people die every year. Especially in South Asia and the Western part of WHO regions, motorcycle traffic deaths are $34 \%$ higher than other areas like Europe, USA, Africa, and Eastern Mediterranean [2]. The number of motorcycle users is increasing rapidly all over the globe, especially in the SouthAsian region. Reports of injuries and accidental death rates of motorcycle riders are also alarming in this region in comparison to other on-road vehicles [2].

The cause of on-road casualties for men aging between 15 29 yrs. is associated with motorcycles. Out of many plausible causative factors for the spike in accidents, un-headgear, drunk-ride, and lack of riding skills are reported to be the significant reasons for motorcycle mishaps. Few of these reasons are strictly enforced by law in South-Asian counties like India, China, Malaysia, amongst others. The use of law enforcement in drunk and driving cases has reduced death rates by $20 \%$. While the implementation of strict rules and regulations may control many of these issues, riding skills can only be improved through better availability of training facilities.

Training using a motorcycle simulator is a useful measure in this direction. The use of the simulator for training purposes is very limited in the South-Asian region due to lack of awareness and the high cost of the commercially available simulator. From literature, it is observed that amongst the notable simulators, MORIS Motorcycle Simulator, Postura Motergo [3], University of Padova Motorcycle Simulator (UNIPD), and Honda Smart Trainer are used in Malaysia and India, respectively. It has also been found that there is a lack of credible information like research publications on motorcycle dimensions. Non-availability of the dimensional database (of different types of motorcycles), which is essential for simulator design, is the main hindrance of developing the low-cost locally manufactured simulators.

\subsection{Market survey and literature review on existing measuring devices}

Usually, these mechanical measuring techniques are used in industries to digitize heritage components, reverse engineering of products, or inspect product quality improvement. Measuring techniques are classified generally as non-contact and contact measurement techniques. The appropriate measuring instrument and/ or technique can be determined according to the product's or its component's characteristics. The presently available measurement techniques are as follows: (a) 3D scanner, (b) Coordinate measuring machine (CMM), and (c) Computed Tomography (CT) X-ray 3D.

3D scanner: The three-Dimensional scanner employs several technologies together like laser line system, structured light system, multi-view camera system, and millimeter waves $[4,5]$.

In 3D scanners with a laser line system, it is mandatory to move the sensor to observe the product. It provokes a higher level of errors [6]. These systems are affordable and easily portable with few tripods (approx. 10000 US\$) [4]. However, 
the working space provided $(200 \mathrm{~mm} \times 200 \mathrm{~mm} \times 200 \mathrm{~mm})$ by this kind of system is not sufficient for motorcycle measurements [7].

The structured light 3D scanner works in a stereovision system. It has the same working principle through which humans perceive the world [8]. Usually, a structured light system uses only one camera and projected stripes for observing the 3D object surface. This system is easily movable and portable, less expensive, and assures faster scanning than other 3D scanners $[9,10]$. These systems have problems with detecting pixels $(640 \times 480 \mathrm{px})$ under the shadow in outdoor environments. This problem generates false detections due to reflection from a nearby reflective surface [8]. Therefore, this system is not satisfying enough to be used in motorcycle measurement applications.

A multi-view camera is another method of observing 3D cloud points extracted from a $3 \mathrm{D}$ object using one or more cameras at different viewing points $[4,11]$. In this method, an experimental observation is made through a single handle held device (camera or iPhone/Smartphone) by a person, 360 degrees around the object with a different angle of focus to capture more pictures at each approximate position. The captured images are converted into CAD files (.stl and .obj) using online open-source software [12-17]. This method of scanning techniques is quite cheaper, portable, and affordable than other 3D scanning devices. This method satisfies all our motorcycle-measuring requirements. However, this technology has disadvantages; one amongst them is the poor capturing of good data for specific surface materials of highly specular products [18]. This method can be performed in close-range photography, which is applicable for small heritage products but not for a massive product like a motorcycle [13, 15].

The millimeter-wave method works under the principle of distinction between active and passive millimeter-wave scanners. The millimeter-wave passes through an object or human, while passive scanners process the emitted waves from objects or humans to observe the $3 \mathrm{D}$ cloud points [4]. This method is usually used in textile industries or airports for luggage and passenger scanning. Such scanners are not meant for mechanical industry usage. However, it has the advantage of scanning through clothes or covered material.

Coordinate measuring machines (CMM): A contact or noncontact probe fixed with a movable 3 -axis arm obtains the 3D cloud points of objectives. An operator or computer programming may control this instrument and can be used to measure an object [19]. This instrument has a higher level of application in mechanical industries $[20,21]$. The contact probes are portable and provide a higher level of accuracy as compared to non-contact laser probes [22-24]. However, this instrument has constrained workspace for measurement, which may not be suitable for motorcycle measurement. These instruments are costly and measure selective coordinate points, which may cause an information gap between two cloud points $[23,25]$.

Computed tomography (CT) X-ray 3D: This scanning method made by $\mathrm{X}$-raying the $3 \mathrm{D}$ object. It is popularly called a C.T. scan in the medical field. This instrument works under the principle of residual radiation passing through a 3D object, which is detected as an X-ray image [25].

This scanning method can scan external and internal shape and geometry, defects of the materials of an object. However, this scanning method has the same drawbacks as CMM [26] Thus, this scanning method is also not suitable for motorcycle measurement. Available 3D coordinate measuring techniques and devices are not only costly but also unable to satisfy diverse requirements of motorcycle measurements.

\subsection{Aim}

From the literature survey, it is observed that the available measuring techniques and devices are not only costly but also unable to satisfy the diverse requirements of motorcycle measurements. Hence, the present research aims to develop an easily portable and affordable measuring device for motorcycles and to use the same for preparing the dimensional database of different motorcycles.

\section{METHOD}

The methodology followed following the sequential steps to accomplish the objectives:

1. Selection of key dimensions of the motorcycle

2. Market and literature survey on existing instruments to measure the key dimensions

3. Design and development of new device via the adaptive design process

4. Testing the level of accuracy of the newly designed equipment through field trial on the field through the standardized operation/ measurement procedure

5. Descriptive statistical analysis using IBM SPSS 24.0 for all the critical dimensions

\subsection{Key dimensions and landmark's definition}

According to IS 11432: 2002 standards, planes, and axis of the motorcycle are defined as shown in Figure 1, which must be considered during the measurement of the motorcycle's key dimensions.

Eight key dimensions were measured at the xz plane (Figure 2 ), which were chosen from the earlier published research articles [27-29]. These dimensions were measured via landmarks such as SIP (Seat Index Point), D-Point (Design point), Origin point, and Footrest point. Locations of these landmarks are described here for easy understanding by the readers. The SIP (or SRP - seat reference point) is a notional location corresponding to the furthest forward position on the seat and the lowest point on the seat [30]. G'-Point is located at the center of handle grip circular face. D-point is situated at the end of the rider seat, which is the highest point of the seat in the motorcycle's xz plane [31]. Fuel tank length is the distance between the extreme corner points of the fuel tank at the xz plane. Footrest point is located at the farthest end of the footrest grip's good portion. The origin point is located at a distance of $1000 \mathrm{~mm}$ along the $\mathrm{X}$-axis and $350 \mathrm{~mm}$ from the floor (ground) [27, 29]

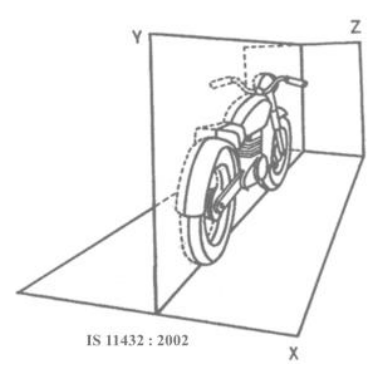

Figure 1. Definition of planes and axis of the motorcycle 


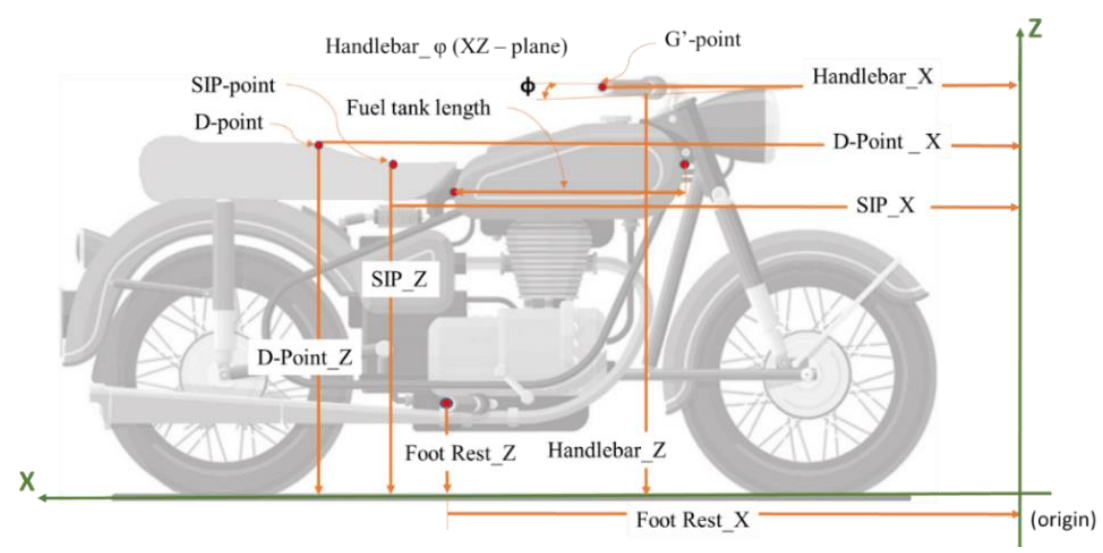

Figure 2. Definition of motorcycle's key dimensions at the xz plane

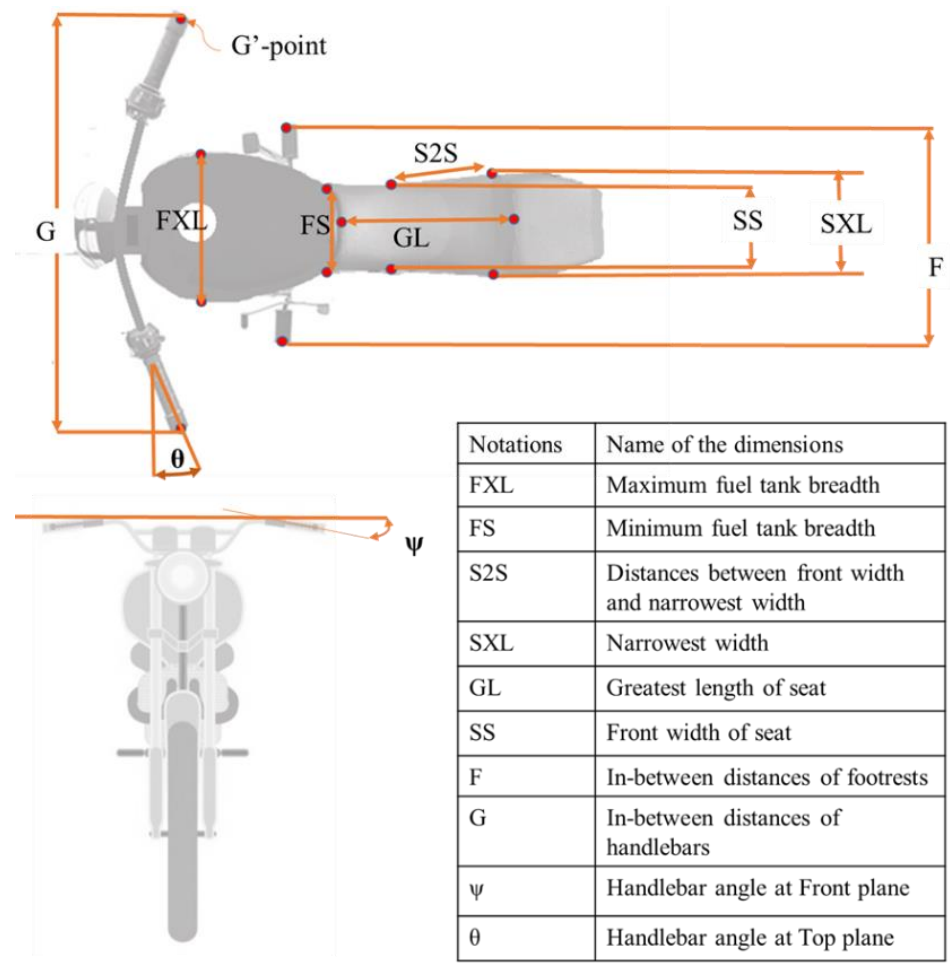

Figure 3. Definition of motorcycle's key dimensions of handlebar, seat, fuel tank and footrest

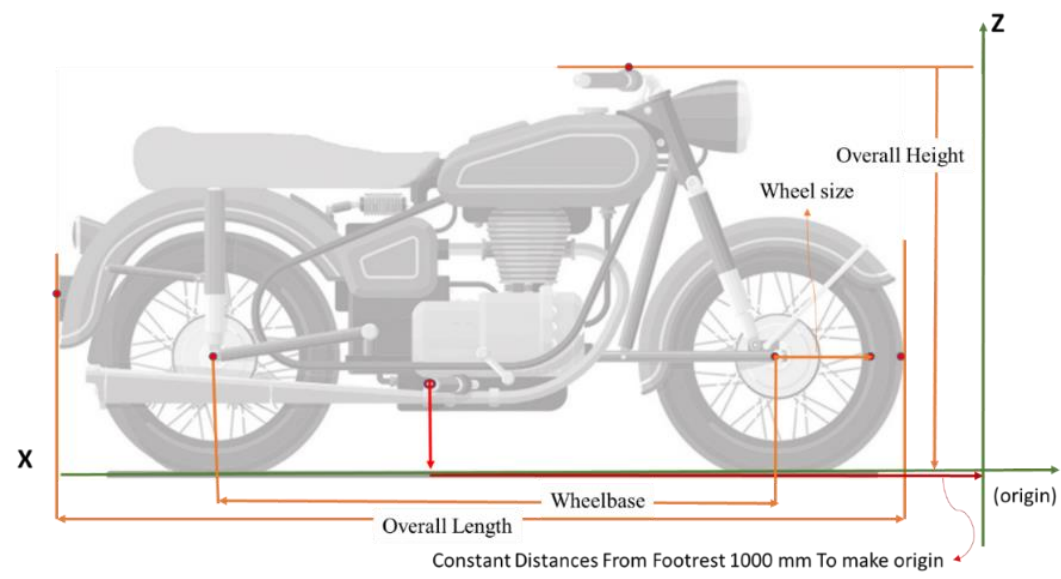

Figure 4. General dimensions of a motorcycles

Since the remaining ten dimensions (as shown in Figure 3) are also required for the basic construction of motorcycle simulators [3], the dimensions were measured using a standard procedure which is recognized in the previously published research articles [32-35]. These dimensions were measured through landmarks in handlebar, seat, fuel tank, and footrest. 
A large sliding caliper (GPM Anthropological instruments model 101; range: $0-1500 \mathrm{~mm}$ and accuracy of $\pm 0.1 \mathrm{~mm}$ ) was used to measure the FXL, FS, S2S, SXL, SS and F. Tape (Size: $1500 \mathrm{~mm} \times 130 \mathrm{~mm}(\mathrm{~L} * \mathrm{~W})$ ) was used to measure the GL. Angular $(\phi, \theta$ and $\psi)$ measurements were recorded using a large protractor (Model name: Thermo - Protractor and Size $500 \times 280 \mathrm{~mm})$.

The measuring technique/instruments should comply with the below following requirements, which may be used to measure the eight dimensions (at $\mathrm{xz}$ plane). These requirements led to identifying a proper measuring technique/instrument for the motorcycle key.

The requirements of the motorcycle's key dimensional measurements are as follows: All motorcycles are measured in the coordinate system (xz) and maintains a common origin point $(0,0)$, since the general dimensions are provided in motorcycle company websites. The measuring technique/instruments may consider the wheelbase, overall length, overall breadth, overall height, and wheel size as their calibration dimensions (as shown in Figure 4). Most of the motorcycles' maximal volume observed to be $1830 \mathrm{~mm} \times$ $915 \mathrm{~mm} \times 1524 \mathrm{~mm}(\mathrm{~L} \times \mathrm{B} \times \mathrm{H})$. Thus, these dimensions must be addressed by the measuring technique/ instruments as the minimal working space. Further, some of the general criteria/ requirements may help a hassle-free field study such as portable, affordable, less time taking for measurements, allows outdoor usage, and high accuracy level (at least $0.1 \%$ of mentioned workspace volume). Moreover, these requirements help in the guideline to identify the best suitable measurement technique/ instruments to measure the eight dimensions (at xz plane of motorcycles).

\subsection{Design process}

Generally, the design process can be classified into three types: (1) originality, (2) adaptive, and (3) variant design process. The selection of a design process depends upon the requirements and the existing products (instruments) in the market. From the market survey, it was observed that none of the available devices were able to fulfill the conditions, which was the demand for the current case of a motorcycle. The adaptive (product) design process, as explained by Meißner and Blessing [36] and Wilmsen et al. [37] was followed for the current study. Depending on the requirements of the current (mentioned in subsection 2) and working principle of earlier development by Chou and Hsiao [38], modularization (modification of specific parts) of the measuring instrument was done during the adaptive design process. Chou and Hsiao [38] used a laser-based instrument to measure the scooter riders' $2 \mathrm{D}$ coordinates at $2 \mathrm{D}(\mathrm{xy})$ plane. Further, this technique is fulfilling the requirement of the current study. Thus, the principle of design has been inspired by this study for further modification using the adaptive design process to fulfill our current study requirements and satisfy the IS 11432: 2002 completely.

The design is adaptive for developing a laser pointer-based 2D coordinate measuring device, as shown in Figure 5. It consists of 5 major parts: $\mathrm{X}$-axis rails frame, sliding base (Xaxis), Rod-stick (as Z-axis), Laser pointer holder, and Laser pointer. The sliding support allows the $Z$-axis rod-stick to move through the $\mathrm{X}$-axis rail frame. The laser pointer affixed in the laser holder can also move along the Z-axis rod-stick during the measurement. Both rail frame (X-axis) and rod stick (Z-axis) have adhered to rulers.

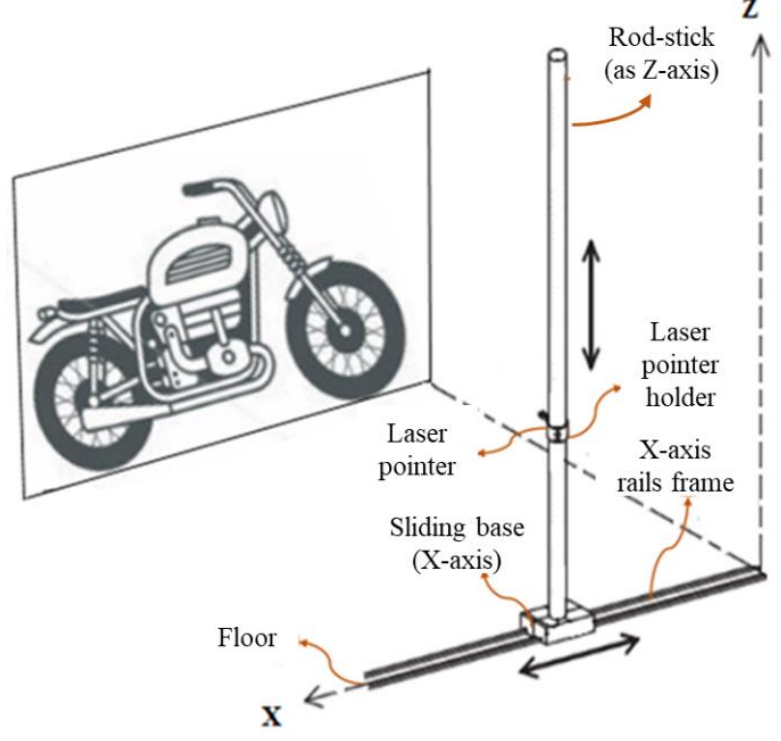

Figure 5. Working principles of design and its parts

A conceptual model was designed using the CAD model for the further design process following the earlier mentioned working principles. Figure 6 shows the proposed concept, which follows the working as mentioned in earlier principles of the measuring device. Following are the functional descriptions of the proposed measuring device:

A. The $\mathrm{X}$-axis rail frame (C-section) is to maintain the straight runway path in X-axis. It is $2500 \mathrm{~mm}$ long, which can help to measure all the dimensions (including calibration dimensions).

B. The support wheel is attached with rod-stick holder and movable along with it. It helps to maintain balance/stability from the rod-stick Z-axis frame's selfweight during measurement and gives us an error-free measure.

C. Connector (bolt and nuts) is used in integrating the $2500 \mathrm{~mm} X$-axis rail frame. Its helps in portability/foldability of measuring device during outdoor measurement.

D. Rod-stick holder is used to integrate the rod-stick Z-axis frame and $X$-axis rails frame for uniform measurement.

E. Inside connector has been provided to integrate the pieces of rod-stick Z-axis frames. It helps in mobilization of the device during outdoor measurement.

F. Rod-stick holder frames are pasted with a ruler-tape of $2000 \mathrm{~mm}$.

G. The laser holder supports the movement along with the rod-stick Z-axis frames for the Z-axis measurement. It provides space to grip the laser pointer.

H. Laser pointer pen could use for pointing the landmarks during measurements. Since laser beam travels through air medium in a straight line, it has been used to locate the motorcycle's landmark.

I. A rigid platform has been provided to give stability and a parallel plane is maintained during measurement. This detachable wooden block can be used for platform rigidity 


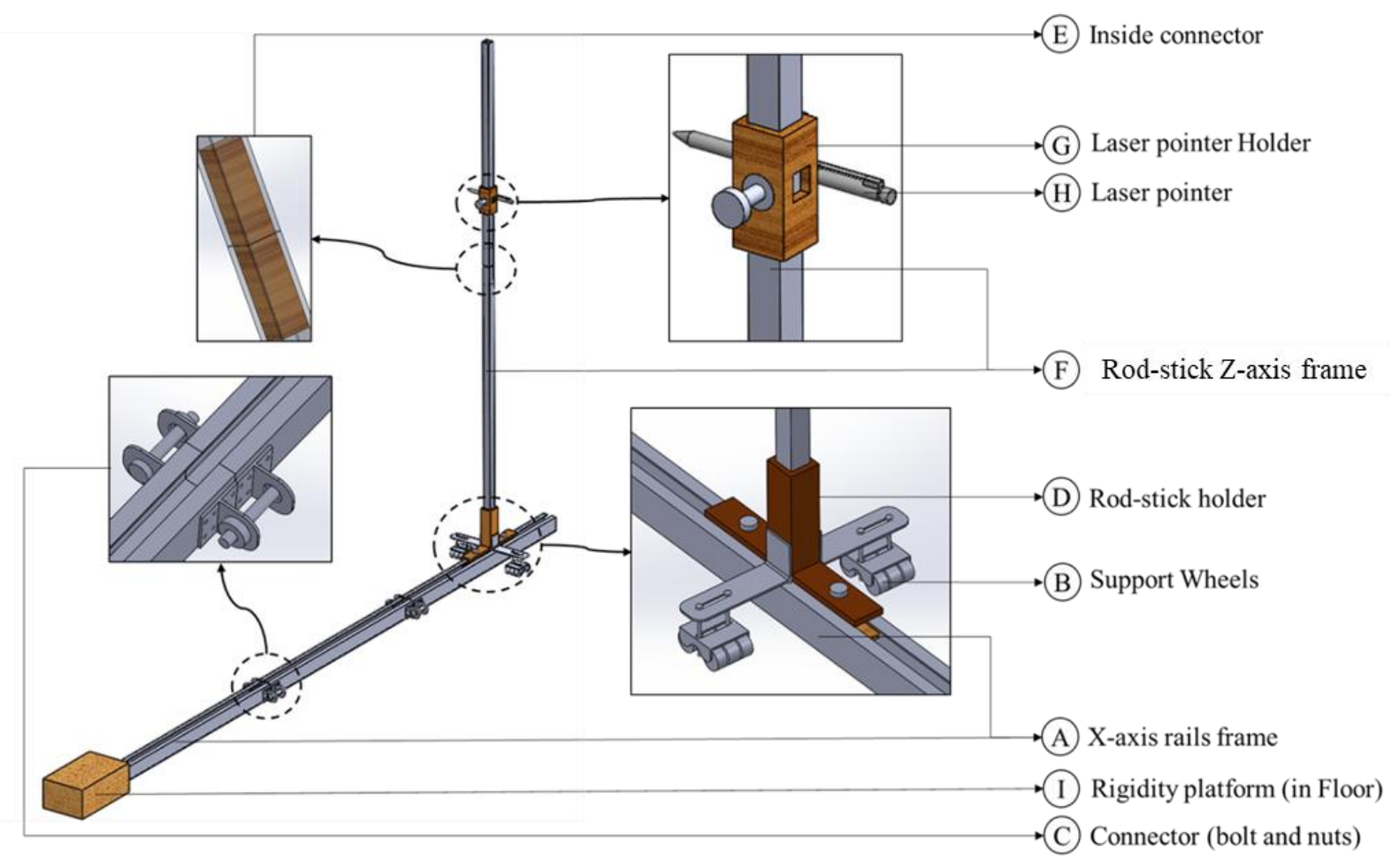

Figure 6. Proposed measuring device and its main parts

Overall, the proposed concept was able to address all the requirements of the current study. To further fabricate the functional prototype, the bill of material (BOM) was generated for the idea. The concept-cost estimations were calculated based on local shop purchase quotations. The total fabrication cost (GTFC) estimated for the concept was 42 \$ (INR 3000). The cost components can be listed as: labor charge,14 \$ (INR 1000); material price, 14 \$ (INR 1000); and manufacturing cost, 14 \$ (INR 1000). The cost estimation for the developed concept was significantly cheaper than other measuring instruments available in the market.

Before prototyping the proposed concept, the finite element analysis (FEA) test was performed using COMSOL 4.3 to identify the deflection caused by the Z-axis rod-stick frame's self-weight and generated errors during the measurement. The material selected for the proposed concept was aluminium (aluminium channels 1000 series). The FEA test discloses that the Z-axis rod stick's self-weight displacement was $0.044 \mathrm{~mm}$ in X-direction, and total deflection was $0.144 \mathrm{~mm}$. These displacements were found to be negligible.

The BOM was prepared using ISO A4 drawing sheets to purchase the materials. An alpha prototype was fabricated in the institute workshop. The developed alpha prototype checked for initial error and calibrations using scales/rulers. A portable bag was made to carry the newly developed measuring device (alpha prototype) for the field study.

\subsection{On-field measurement procedure using an in-house fabricated measuring device}

A total 23 (standard or economic segment) motorcycle's key dimensions were measured in the motorcycle showrooms (Figure 7). The 23 motorcycles include the popular motorcycle models (as listed in Table 1). Before commencing the data collection i.e. measuring the key dimensions at the $\mathrm{xz}$ - plane, a newly developed measuring device was calibrated using know dimensions like (wheelbase, overall length, and overall height).
The key dimensions measured followed a standard operating procedure (SOP). The SOP, Step 1 was to make the center point of the footrest fix at the distance of $1000 \mathrm{~mm}$ from the $\mathrm{x}$-axis origin and $350 \mathrm{~mm}$ from the $\mathrm{z}$-axis origin. Step 2, involved measuring the calibration dimensions (like overall length, overall height, and wheelbase) as per IS 11432: 2002 instructions. Each calibration dimension was measured twice for better clarification. Following the calibration process, landmarks of the handlebar and seat were located. Further, eight key dimensions (at XZ plane) were measured from the origin. After these measurements, key aspects of the handlebar, seat, fuel tank, and footrest (like FXL, FS, S2S, SXL, SS, GL, $\mathrm{F}, \phi, \theta$, and $\psi$ ) were measured using a large sliding caliper and large protractor. The whole duration of the field measurement for a single motorcycle was approximately 1 hour.

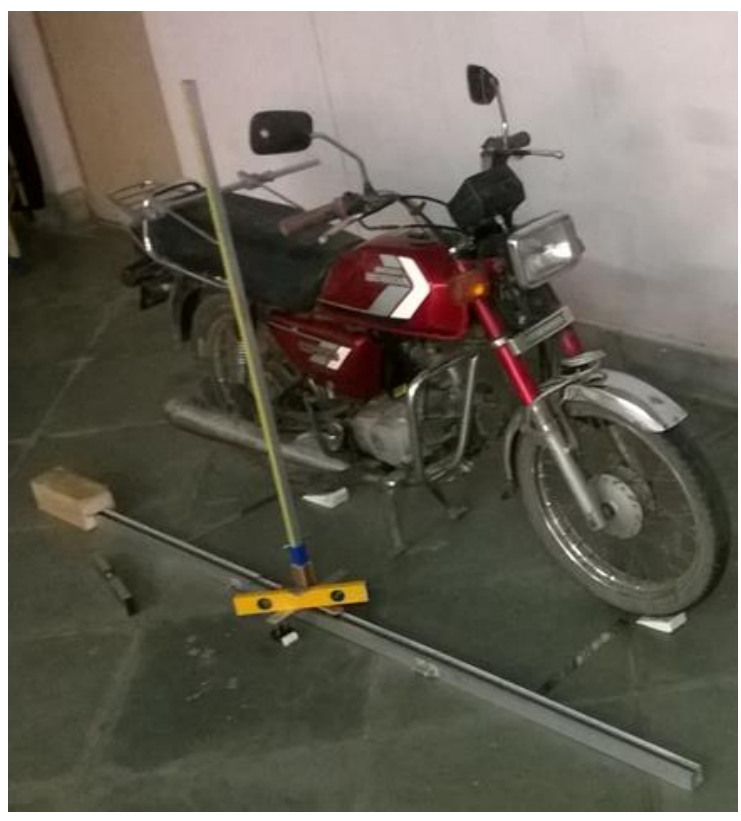

Figure 7. Measurement setup with the new measuring device 


\section{RESULTS AND DISCUSSION}

\subsection{Accuracy analysis of newly developed measuring device}

The newly developed device is used for data collection and to estimate the error of the 23 motorcycles. The data-collection method followed an SOP to measure dimensions. The overallheight, overall-length, and wheelbase dimensions were analyzed using comparative analysis. The dimensions' actual value is the reference from the motorcycle company's websites. The mentioned measured values noted during the first trial of measurements. The accuracy was assessed through the percentage of relative error (Error\%), alterative-reliability (Pearson correlation), and Bland Altman plot. The relative error was calculated between actual and measured dimensions. The relative error percentage (Error\%) estimated using the following Eq. (1).

$$
\text { Error } \%=\frac{\text { Actual }- \text { measured }}{\text { Actual }} \times 100
$$

where, Actual is the real dimension of the motorcycle's overall length/overall height/wheelbase; Measured is observed dimension of the motorcycle's overall length/overall height/wheelbase using a new device.

Table 1 shows the overall length, overall height, wheelbase of relative error provoked during field measurement. Error\% of overall length, overall height, wheelbase was estimated in the range from $-0.152 \%$ to $0.153 \%$, from $-0.297 \%$ to $0.287 \%$, from $0 \%$ to $0.238 \%$, respectively. Among this error $\%$, overall length error\% was found to be relatively lesser than the overall height and wheelbase.

Overall, relative errors estimated at a maximum of $0.5 \%$. This error\% of all the dimensions was within the tolerances limit of $\pm 0.5 \%$. Also, the errors of each motorcycle's dimensions estimated to be negotiable and less.

The comparative analysis was performed between the differences of two measures (existing measurement - newly developed device's measurement) (as shown in Figure 8) using Bland Altman plot techniques [39]. This plot was drawn using SPSS for overall length (see Figure 8-A), wheelbase (see Figure 8-B), and overall height (see figure 8-C) dimension to evaluate the accuracy of the newly developed device. For the aforesaid plot, the upper bound (UL) and lower bound (LL) was estimated at the confidence intervals of $95 \%$, using mean (M) and standard deviation (SD).

The Bland Altman plot of overall length shows that only one outlier measurement falls beyond the upper limit and lower limit of the differences. Likewise, in the wheelbase measurements, two outlier measurements were found beyond the lower limit of the difference (of wheelbase measurements). However, in the case of overall height, no outliers were found. Moreover, most of them were within the confidence interval (between upper and lower limits) in Bland Altman plots. Therefore, the dimensions measured by the newly developed device would be reliable and trustworthy.

The alterative-reliability was evaluated through the Pearson correlation coefficient. The coefficient was estimated between the actual measures of overall length/overall height/wheelbase and measurements observed using the new device. The correlation coefficient of overall-length, overall-height, and wheelbase was estimated at 0.999, 0.998, and 0.999, respectively.
Furthermore, this correlation coefficient was within the reliable limit of 0.980 . Thus, the new device was found to be reliable.

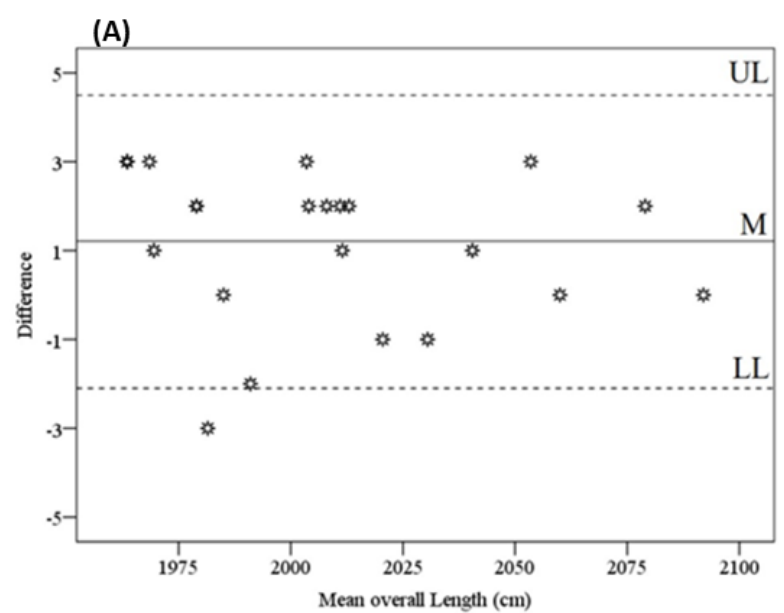

(B)

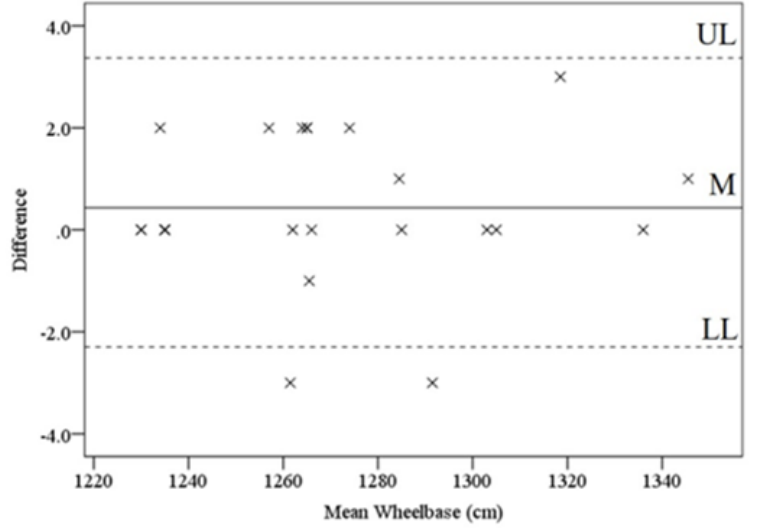

(C)

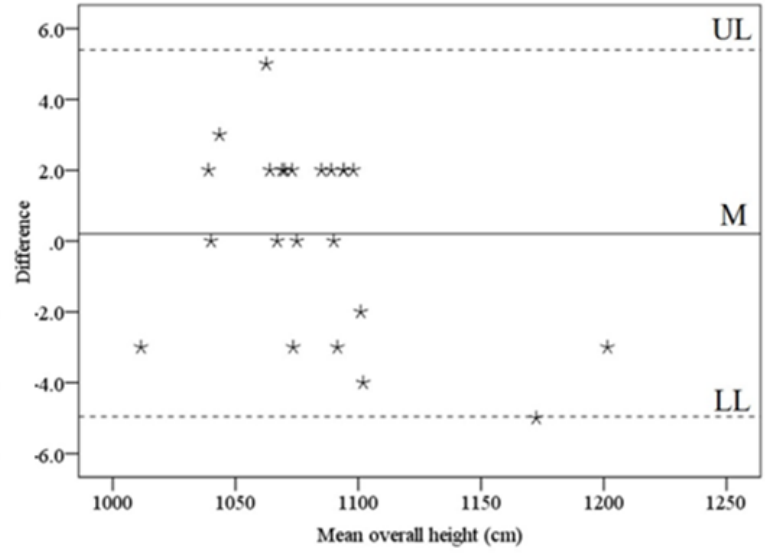

Figure 8. Bland Altman plot - (A) overall length; (B) overall height and $(\mathrm{C})$ wheelbase

Further to check the correctness (accuracy) and applicability of the device, general dimensions (overall-length, overall-height, and wheelbase) of 3 scooters (different types of motorcycles) were measured using the newly developed/ fabricated device. The comparative result between the actual and measured dimensions was found within the allowable error-limit (correlation coefficient of 0.980). Moreover, the new device's applicability for measuring the scooters' (other types of motorcycle) dimensions was observed to be easy and hassle-free. 
Table 1. Percentage of relative error of new device (Unit: mm; Unless defined)

\begin{tabular}{cccccccccc}
\hline \multirow{2}{*}{ Models of motorcycles } & \multicolumn{3}{c}{ Overall length } & \multicolumn{3}{c}{ Overall Height } & \multicolumn{3}{c}{ Wheelbase } \\
\cline { 2 - 9 } & Actual & Measured & Error\% & Actual & Measured & Error\% & Actual & Measured & Error\% \\
\hline Baja CT 100 & 1965 & 1962 & 0.153 & 1072 & 1075 & -0.280 & 1235 & 1235 & 0.000 \\
Pulsar 150 & 2055 & 2052 & 0.146 & 1170 & 1175 & -0.427 & 1320 & 1317 & 0.227 \\
Discover 150 & 2030 & 2031 & -0.049 & 1065 & 1060 & 0.469 & 1305 & 1305 & 0.000 \\
XCD 125 & 1980 & 1978 & 0.101 & 1200 & 1203 & -0.250 & 1275 & 1273 & 0.157 \\
Apache & 2080 & 2078 & 0.096 & 1100 & 1102 & -0.182 & 1303 & 1303 & 0.000 \\
Victor & 1980 & 1983 & -0.152 & 1090 & 1088 & 0.183 & 1260 & 1263 & 0.238 \\
Phoenix & 1985 & 1985 & 0.000 & 1065 & 1063 & 0.188 & 1265 & 1263 & 0.158 \\
Star city & 1990 & 1992 & -0.101 & 1010 & 1013 & -0.297 & 1262 & 1262 & 0.000 \\
CD shine & 2014 & 2012 & 0.099 & 1071 & 1069 & 0.187 & 1266 & 1264 & 0.158 \\
CD livo & 2020 & 2021 & -0.050 & 1099 & 1097 & 0.182 & 1285 & 1285 & 0.000 \\
CB 125 shine & 2012 & 2011 & 0.050 & 1090 & 1093 & -0.275 & 1266 & 1264 & 0.158 \\
CB unicorn & 2092 & 2092 & 0.000 & 1100 & 1104 & -0.364 & 1336 & 1336 & 0.000 \\
Dream yoga & 2005 & 2003 & 0.100 & 1095 & 1093 & 0.183 & 1285 & 1284 & 0.078 \\
Splendor & 1970 & 1969 & 0.051 & 1040 & 1038 & 0.192 & 1230 & 1230 & 0.000 \\
Hero glamor & 2005 & 2002 & 0.150 & 1070 & 1068 & 0.187 & 1265 & 1266 & 0.079 \\
passion pro & 1980 & 1978 & 0.101 & 1075 & 1075 & 0.000 & 1235 & 1235 & 0.000 \\
ismart & 1965 & 1962 & 0.153 & 1095 & 1093 & 0.183 & 1235 & 1233 & 0.162 \\
Splendor pro & 1970 & 1967 & 0.152 & 1040 & 1040 & 0.000 & 1230 & 1230 & 0.000 \\
Dream neo & 2009 & 2007 & 0.100 & 1074 & 1072 & 0.186 & 1258 & 1256 & 0.159 \\
Optimax 125 & 2012 & 2010 & 0.099 & 1090 & 1090 & 0.000 & 1266 & 1266 & 0.000 \\
HF Deluxe & 1965 & 1962 & 0.153 & 1045 & 1042 & 0.287 & 1235 & 1235 & 0.000 \\
Honda Hornet & 2041 & 2040 & 0.049 & 1067 & 1067 & 0.000 & 1346 & 1345 & 0.074 \\
Achiever & 2060 & 2060 & 0.000 & 1086 & 1084 & 0.184 & 1290 & 1293 & 0.233 \\
\hline
\end{tabular}

Table 2. Raw dimensions of 23 Motorcycle's key dimensions at XZ plane (Unit: mm)

\begin{tabular}{ccccccc}
\hline \multirow{2}{*}{ Models of Motorcycles } & \multicolumn{2}{c}{ G'-point } & \multicolumn{2}{c}{ SIP } & \multicolumn{2}{c}{ D-point } \\
& $\mathbf{X}$ & $\mathbf{Z}$ & $\mathbf{X}$ & $\mathbf{Y}$ & $\mathbf{X}$ & $\mathbf{Z}$ \\
\hline Baja CT 100 & 840 & 1075 & 1200 & 730 & 1470 & 890 \\
Pulsar 150 & 710 & 1045 & 1170 & 830 & 1380 & 920 \\
Discover 150 & 850 & 1088 & 1300 & 870 & 1550 & 920 \\
XCD 125 & 830 & 1070 & 1280 & 880 & 1480 & 920 \\
Apache & 590 & 970 & 1200 & 900 & 1320 & 1100 \\
Victor & 810 & 1070 & 1490 & 880 & 1250 & 860 \\
Phoenix & 770 & 1120 & 1280 & 890 & 1500 & 940 \\
Star city & 800 & 1075 & 1260 & 870 & 1440 & 920 \\
CD shine & 760 & 1070 & 1250 & 830 & 1430 & 870 \\
CD livo & 800 & 1085 & 1290 & 860 & 1510 & 910 \\
CB 125 shine & 780 & 1055 & 1240 & 830 & 1430 & 860 \\
CB unicorn & 740 & 1080 & 1240 & 840 & 1490 & 890 \\
Dream yoga & 770 & 1075 & 1240 & 890 & 1450 & 940 \\
Splendor & 800 & 1030 & 1260 & 810 & 1470 & 860 \\
Hero glamor & 770 & 1118 & 1240 & 860 & 1450 & 930 \\
passion pro & 820 & 1060 & 1170 & 890 & 1390 & 910 \\
ismart & 760 & 1095 & 1210 & 860 & 1390 & 930 \\
Splendor pro & 790 & 1065 & 1190 & 850 & 1420 & 890 \\
Dream neo & 770 & 1075 & 1240 & 890 & 1450 & 940 \\
Optimax 125 & 780 & 1055 & 1240 & 830 & 1430 & 860 \\
HF Deluxe & 800 & 1030 & 1260 & 810 & 1470 & 860 \\
Honda Hornet & 560 & 1030 & 1050 & 840 & 1305 & 920 \\
Achiever & 800 & 1085 & 1290 & 860 & 1510 & 910 \\
\hline & & & & &
\end{tabular}

\subsection{Descriptive analysis of key dimensions}

23 Motorcycle's key dimensions at the xz plane were presented in Table 2. Further, it was analyzed using IBM SPSS 24.0. The descriptive statistics have been shown through the mean, standard deviation (SD), maximum, and minimum for each motorcycle's key dimension. Table 3 presents the descriptive statistics of key dimensions of among all the 23 motorcycles

The measured variations of $\mathrm{G}^{\prime}$ - points for the handle (left/right) were found to be 560 to $990 \mathrm{~mm}$ for forward/backward direction, 970 to $1155 \mathrm{~mm}$ for the vertical direction, and 690 to $770 \mathrm{~mm}$ for In-between distance of Handlebar $(\mathrm{G})$. The variations of In-between distance of footrests $(\mathrm{F})$ were found to be 540 to $590 \mathrm{~mm}$. The measured variation of coordinate points for the seat's D-point was found to be 1250 to $1550 \mathrm{~mm}$ for forward/ backward direction, 860 to $1100 \mathrm{~mm}$ for the vertical direction. Regarding SIP-point of the seat, 1050 to $1490 \mathrm{~mm}$ for forward/ backward direction, 730 to $900 \mathrm{~mm}$ for the vertical direction.

The 23 standard motorcycle models having the following seat dimensions of front width (SS) (mean: 160 mm; SD: \pm 20 
$\mathrm{mm}$ ), narrowest width (SXL) (mean: $210 \mathrm{~mm}$; SD: $\pm 20 \mathrm{~mm}$ ), the distance between the front width and smallest width (S2S) (mean: $150 \mathrm{~mm}$; SD: $\pm 20 \mathrm{~mm}$ ) and the greatest length (GL) (mean: $360 \mathrm{~mm}$; SD: $\pm 22 \mathrm{~mm}$ ). The minimum and maximum fuel tank breadths were found between 130 and $250 \mathrm{~mm}$ and from 280 to $420 \mathrm{~mm}$, respectively. The size of the Fuel tank length was a range from 340 to $520 \mathrm{~mm}$. The mean (M) and $\mathrm{SD}$ of handlebar angles were measured as $\phi$ is $\mathrm{M}: 3^{\circ}$ (SD: 2 ); $\psi$ is $\mathrm{M}: 7^{\circ}$ (SD: 3 ); $\theta$ is $20^{\circ}$ (SD: 5 ).

Most of the dimensional variations were recorded to be very minimal. The maximum SD was found in SIP_X (seat dimension). However, all the observations were in-line with existing standards $[31,33]$.

The study has few limitations that the overall relative error of the newly designed instrument is estimated as a maximum of $0.5 \%( \pm 1 \mathrm{~mm})$ in comparison to FaroArm, (2019) [23] and CMM [19] where the accuracies are $0.05 \%( \pm 0.1 \mathrm{~mm})$ and $0.001 \%( \pm 0.01 \mathrm{~mm})$, respectively. However, the new device's accuracy is good enough for measuring larger dimensions of a motorcycle or its components.

Table 3. Descriptive statistics of the motorcycle key dimensions (Unit: mm; unless specified)

\begin{tabular}{|c|c|c|c|c|}
\hline Key dimensions & Minimum & Maximum & Mean & SD \\
\hline Handlebar_X & 560 & 850 & 770 & 69 \\
\hline Handlebar Z Z & 970 & 1120 & 1066 & 32 \\
\hline SIP_X & 105 & 1490 & 1243 & 76 \\
\hline SIP $Z$ & 730 & 900 & 852 & 38 \\
\hline D-point_X & 1250 & 1550 & 1434 & 71 \\
\hline D-point_Z & 860 & 1100 & 911 & 50 \\
\hline Handlebar ф (Unit: $\left.{ }^{\circ}\right)$ & 0 & 8 & 3 & 2 \\
\hline Fuel tank length & 340 & 520 & 447 & 53 \\
\hline Maximum fuel tank breadth (FXL) & 280 & 420 & 332 & 35 \\
\hline Minimum fuel tank breadth (FS) & 130 & 250 & 188 & 31 \\
\hline Distance between front width and narrow width (S2S) & 110 & 180 & 150 & 20 \\
\hline Narrowest width (SXL) & 190 & 230 & 214 & 13 \\
\hline Greatest length of seat (GL) & 310 & 410 & 358 & 22 \\
\hline Front width of seat (SS) & 140 & 190 & 162 & 15 \\
\hline In-between distance of footrests (F) & 540 & 590 & 566 & 20 \\
\hline In-between distance of Handlebar (G) & 690 & 770 & 732 & 24 \\
\hline Handlebar angle at Front Plane $(\psi)\left(\right.$ Unit: $\left.^{\circ}\right)$ & 10 & 11 & 7 & 3 \\
\hline Handlebar angle at Top Plane $(\theta)\left(\right.$ Unit: $\left.^{\circ}\right)$ & 25 & 15 & 20 & 5 \\
\hline
\end{tabular}

Note: G'-point at handlebar; SIP and D-point at seat. During these measurements, footrest fix at the distance of $1000 \mathrm{~mm}$ from the $\mathrm{x}$-axis origin and $350 \mathrm{~mm}$ from the $\mathrm{z}$-axis origin

\section{CONCLUSION}

The laser pointer based measuring device designed in the present research was light-weight (main structure made up of aluminum, $7 \mathrm{~kg}$ ), with easy assemble/ dismantle feature (sliding channel, clamp and nut-bolt mechanism), low cost (estimated INR 3000), and capable of measuring the key dimensions within the volume of $1830 \mathrm{~mm} \times 915 \mathrm{~mm} \times 1524$ $\mathrm{mm}$ (length $\mathrm{x}$. breadth $\mathrm{x}$ height). The maximum values of relative errors were found to be $0.153 \%$ for overall length, $0.287 \%$ for overall-height, and $0.238 \%$ for the wheelbase. Bland Altman plot and Pearson correlation coefficient results were found to be reliable.

It is expected that the measured database on dimensional variability of key dimensions of the three main contact points of the human-motorcycle interface would be useful for deciding the dimensions of the motorcycle simulator and many other similar applications.

\section{ACKNOWLEDGMENT}

The authors would like to thank the Ministry of Human Resource Development (MHRD) and research under the Design Innovation Centre (DIC) project. The authors would like to thank all the motorcycle-showrooms' owners who allowed to perform the measurement survey.

\section{REFERENCES}

[1] Bacci, M.L. (2017). A Concise History of World Population. John Wiley \& Sons.

[2] World Health Organization. (2015). WHO - Road Traffic Accidents. None 2015.

[3] Ma'arof, M.I.N., Omar, A.R., Ahmad, I.N., Jaafar, R., Fauzi, W., Rahim, A.A., Rashid, H., Mahmud, Z. (2015). The motorcycle design parameter database (MDPD) for different motorcycle models. Procedia Manufacturing, 3: 2581-2588. http://dx.doi.org/10.1016/j.promfg.2015.07.575

[4] Daanen, H.A., Ter Haar, F.B. (2013). 3D whole body scanners revisited. Displays, 34(4): 270-275. https://doi.org/10.1016/j.displa.2013.08.011

[5] Olds, T., Honey, F. (2006). The use of 3D whole-body scanners in anthropometry. Proceedings of the 9th International Conference of the International Society for the Advancement of Kinanthropometry, pp. 1-12.

[6] Mahmud, M., Joannic, D., Roy, M., Isheil, A., Fontaine, J.F. (2011). 3D part inspection path planning of a laser scanner with control on the uncertainty. Computer-Aided Design, 43(4): 345-355. https://doi.org/10.1016/j.cad.2010.12.014

[7] Borghese, N.A., Ferrigno, G., Baroni, G., Pedotti, A., Ferrari, S., Savarè, R. (1998). Autoscan: A flexible and portable 3D scanner. IEEE Computer Graphics and Applications, 18(3): 38-41. https://doi.org/10.1109/38.674970 
[8] Stančić, I., Musić, J., Zanchi, V. (2013). Improved structured light 3D scanner with application to anthropometric parameter estimation. Measurement, 46(1): $716-726$ https://doi.org/10.1016/j.measurement.2012.09.010

[9] Morimoto, Y., Masaya, A., Ueki, M. (2019). High-speed 3D shape measurement by one pitch phase analysis method using brightness values in small square area of single-shot image. Optics and Lasers in Engineering, 113: 38-46. https://doi.org/10.1016/j.optlaseng.2018.08.023

[10] Rocchini, C., Cignoni, P., Montani, C., Pingi, P., Scopigno, R. (2001). A low cost 3D scanner based on structured light. Computer Graphics Forum, 20(3): 299308. https://doi.org/10.1111/1467-8659.00522

[11] Gai, S., Da, F., Tang, M. (2019). A flexible multi-view calibration and 3D measurement method based on digital fringe projection. Measurement Science and Technology, 30(2): $\quad 025203 . \quad$ https://doi.org/10.1088/1361 6501/aaf5bd

[12] Chowdhury, W.S., Lu, G., Hossain, M.M. (2020). Threedimensional reconstruction and measurement of avian eggs through digital imaging. 2020 IEEE International Instrumentation and Measurement Technology Conference (I2MTC), Dubrovnik, Croatia, pp. 1-5. https://doi.org/10.1109/I2MTC43012.2020.9129156

[13] Kolev, K., Tanskanen, P., Speciale, P., Pollefeys, M. (2014). Turning mobile phones into 3D scanners. Proceedings of the IEEE Conference on Computer Vision and Pattern Recognition, Columbus, OH, USA, pp. 3946-3953. https://doi.org/10.1109/CVPR.2014.504

[14] Baltsavias, M., Gruen, A., van Gool, L., Pateraki, M. (2005). Recording, Modeling and Visualization of Cultural Heritage. CRC Press.

[15] Böhler, W., Marbs, A. (2004). 3D scanning and photogrammetry for heritage recording: A comparison. Proceedings of the 12th International Conference on Geoinformatics, Gavle University Press, Sweden, pp. 291-298.

[16] Muratov, O., Slynko, Y., Chernov, V., Lyubimtseva, M., Shamsuarov, A., Bucha, V. (2016). 3DCapture: 3D reconstruction for a smartphone. Proceedings of the IEEE Conference on Computer Vision and Pattern Recognition Workshops, pp. 75-82. https://doi.org/10.1109/CVPRW.2016.116

[17] Nocerino, E., Lago, F., Morabito, D., Remondino, F., Porzi, L., Poiesi, F., Rota Bulo, S., Chippendale, P., Locher, A., Havlena, M. (2017). A smartphone-based 3D pipeline for the creative industry-the replicate EU project. 3D VIRTUAL Reconstr. Vis. COMPLEX Archit., 42: 535-541. https://doi.org/10.5194/isprs-archives-XLII-2W3-535-2017

[18] Cui, Y., Stricker, D. (2011). 3d shape scanning with a Kinect. ACM SIGGRAPH 2011 Posters, p. 1.

[19] Crampton, S.J. (2008). CMM arm with exoskeleton. Google Patents.

[20] Achelker, C., Rao, N.S., Rajendra, R., Krishaniah, A. (2014). Performance evaluation of machine tool probe for in-process inspection of $2 \mathrm{~d}$ and $3 \mathrm{~d}$ geometries. Procedia Technology, 14: 244-251. https://doi.org/10.1016/j.protcy.2014.08.032

[21] Lin, H.C., Yu, B.R., Wang, J.Y., Lai, J.Z., Wu, J., Peng, C.Y., Chen, C.C. (2020). Realisation of threedimensional geometric model in case of bike frame measurement. IET Circuits, Devices \& Systems, 14(5):
713. https://doi.org/10.1049/iet-cds.2019.0274

[22] Barbero, B.R., Ureta, E.S. (2011). Comparative study of different digitization techniques and their accuracy. Comput.-Aided Design, 43(2): 188-206. https://doi.org/10.1016/j.cad.2010.11.005

[23] FaroArm ${ }^{\circledR}$ - Portable 3D Measurement Arms for any application [WWW Document], n.d. URL https://www.faro.com/en-gb/products/3dmanufacturing/faroarm/, accessed on Mar. 2, 2020.

[24] Rim, C.H., Sun, B.Q., Kim, Y.G., Kim, P. (2019). Analysis of random factors affecting measurement accuracy of portable coordinate measuring arm. MAPAN, 34: 529-539. https://doi.org/10.1007/s12647-019-00323$\mathrm{x}$

[25] Gapinski, B., Wieczorowski, M., Marciniak-Podsadna, L., Dybala, B., Ziolkowski, G. (2013). Comparison of different method of measurement geometry using CMM, Optical Scanner and Computed Tomography 3D. Procedia Engineering, 69: 255-262. https://doi.org/10.1016/j.proeng.2014.02.230

[26] Tóth, T., Živčák, J. (2014). A comparison of the outputs of 3D scanners. Procedia Engineering, 69: 393-401. https://doi.org/10.1016/j.proeng.2014.03.004

[27] Hale, A., Pelowski, D., Bhise, V. (2007). Commonality and differences between cruiser, sport, and touring motorcycles: An ergonomics study (No. 2007-01-0438). SAE Technical Paper. https://doi.org/10.4271/2007-010438

[28] Rajhans, N.R., Kolekar, S. (2011). Design inputs for motorbike riding posture: An anthropometric approach. International conference on Ergonomics and Human Factors, Humanising Work and Work Environment 2011

[29] Sabbah, A.O., Bubb, H. (2008). Development of a motorcycle posture model for DHM systems (No. 200801-1866). SAE Tech. Pep. https://doi.org/10.4271/200801-1866

[30] Robertson, S., Porter, J.M. (1987). Motorcycle ergonomics: An exploratory study. Contemp. Ergon., 173-178.

[31] JASO T003:2009. (2009). Motorcycles-Riding position. JAPANESE AUTOMOBILE STANDARD. https://global.ihs.com/doc_detail.cfm?document_name= JASO\%20T003\&item_s_key=00442741.

[32] Mansfield, N.J., James, P.I. (2001). Development of a seat pad suitable for measuring motorcycle seat vibration. Presented at the 36th United Kingdom Group Meeting on Human Responses to Vibration, held at Centre for Human Sciences, Farnborough, UK.

[33] JASO T102-84. (1975). Handle bar width and grip angle for motorcycles. Japanese Automobile Standard. https://www.bookpark.ne.jp/cm/jsae/select_e.asp?pagen $\mathrm{o}=72$ \&pagenum $=10 \&$ category $=500 \&$ lang $=\&$ table $=$ JSA Q.

[34] SAE J 1241. (2012). Fuel and Lubricant tanks for motorcycles. Society of Automobile Engineers (SAE) International. https://www.sae.org/standards/content/j1241 199911/.

[35] SAE J30. (1998). Fuel and oil Hoses. Society of Automobile Engineers (SAE) International. https://law.resource.org/pub/us/cfr/ibr/005/sae.j30.1998. pdf.

[36] Meißner, M. and Blessing, L. (2006). Defining an adaptive product development methodology. In DS 36: Proceedings DESIGN 2006, the 9th International Design 
Conference, Dubrovnik, Croatia, pp. 69-78.

[37] Wilmsen, M., Dühr, K., Albers, A. (2019). A contextmodel for adapting design processes and methods. Procedia CIRP, 84: 428-433. https://doi.org/10.1016/j.procir.2019.04.243

[38] Chou, J.R., Hsiao, S.W. (2005). An anthropometric measurement for developing an electric scooter.
International Journal of Industrial Ergonomics, 35: 10471063. https://doi.org/10.1016/j.ergon.2005.06.001

[39] Bland, J.M., Altman, D.G. (1999). Measuring agreement in method comparison studies. Statistical Methods in Medical Research, 8: 135-160. 